puede servir como llamada "abrahámica" a la conversión, a salir de si mismo, "salir de su patria y de su parentela hacia la tierra nueva de la Promesa". Es ahi y no en la teoría, según el autor, donde el cristiano se juega su existencia.

José Luis Trechera Herreros

\subsection{PSICOLOGIA SOCIAL}

GONZALEZ PORTAL, $M^{\star}$ D. (1992). Conducta prosocial: evaltación $e$ intervención. Editorial Morata, Madrid, 159 pags.

El objetivo de la autora, profesora de psicología enla Universidad Complutense de Madrid, es doble.

En primer lugar, pretende potenciar la conducta prosocial, como alternativa a la conducta antisocial, en sus dos grandes núcleos: reducción y prevención de la agresión y la delincuencia, por un lado, y por otro potenciación del comportamiento asistencial en oposición a la no deseada inhibición de la conducta social positiva.

En segundo lugar, otro objetivo sería reunir en este texto lo esencial del tema -bastante desconocido por cierto en nuestro pais-, trasmitiendo una idea lo más exacta posible del estado de la cuestión, a dos décadas de sus comienzos, cuando existe ya abundante producción cientifica y comienzan a comercializarse siste- mas de intervención aplicables en la práctica por los profesionales.

Esto lo realiza -utilizando las mismas palabras de la autora- mediante una metodologia de análisis tridimensional, que incluye tres puntos de vista: sociohistórico, teórico-explicativo y empirico-descriptivo.

En los capítulos que engloba el punto de vista socio-histórico, se analiza la evolución del constructo, durante los últimos 20 años, partiendo de la hasta entonces desconocida "inhibición social de ayuda". Los primeros análisis manifestaron con claridad que se trataba de un problema real de enorme interés público. Inicialmente se identificó el nuevo constructo al concepto de altruismo, para posteriormente denominarlo internacionalmente conducta prosocial o de tipo asistencial.

En la parte correspondiente al punto de vista teórico-explicativo, la autora delimita con claridad el concepto de conducta prosocial. Analiza detenidamente sus determinantes y la correlación que según múltiples investigaciones - guarda la conducta prosocial con el proceso de socialización y con otras variables conductuales y de personalidad.

Finalmente, el bloque empírico-descriptivo engloba los distintos tipos de conducta prosocial, Elabora una clasificación minuciosa, partiendo de diversos criterios: conducta solicitada-no solicitada, ayuda directa-indirecta, ayuda indentificable-no identificable, de emergencia-de no emergencia, espontáneano espontánea... 
Termina el libro con dos capitulos prácticos. El primero sobre las posibilidades de intervención de la conducta prosocial y su evaluación mediante tests y situaciones experimentales de laboratorio. El segundo, sobre programas de entrenamiento en habilidades prosociales tanto en la ensenanza como en la clínica.

Con un lenguaje conciso y claro, se trata de un texto interesante para todo psicólogo, sociólogo o educador preocapado por un abordaje científico $y$ operativo a las conductas antisociales.

Alfonso López Caballero

\section{1,1 SINDICALISMO}

ALBA, A. (Comp.). (1992). Teoria económica y análisis empírico de los sindicatos. Ministerio de Trabajo y Seguridad Social, Madrid, 637 págs.

En España la rama de la economía laboral está muy poco desarrollada, y el estudio de los sindicatos desde un punto de vista esirictamente económico es prácticamente desconocido, por esto es de agradecer al Ministerio de Trabajo y Seguridad Social la publicación del libro que reseñamos que es una colección de 22 trabajos de profesores de economía laboral de las más prestigiosas universidades norteamericanas e inglesas, que analizan desde el punto de vista estrictamente de la teoría económica y de los datos empiricos recogidos las organizaciones sindicales como fuerzas económicas.

El hecho de que los trabajos recogidos tomen principalmente como modelo los sindicatos norteamericanos e ingleses en cuyos países se publicaron originalmente estos estudios, y que estas organizaciones obreras anglosajonas difieran en ciertos aspectos (pero menos de lo que generalmente se cree) de los sindicatos europeos en general, y de los españoles en particular, no disminuye el valor de los mismos, aunque conviene tener en cuenta estas diferencias a la hora de aplicar sus conclusiones al caso concreto de nuestro pais.

El libro está dividido en cuatro partes que pretenden contestar a preguntas de tanta actualidad como la forma en que los sindicatos, como agentes económicos, intentan maximizar sus beneficios, el impacto que pueden tener los sindicatos en los niveles salariales y la inflación, la relación entre fuerza sindical y productividad, y la influencia de los sindicatos en la distribución de la renta.

En la primera parte se analizan los dos enfoques clásicos en el estudio del sindicalismo como fuerza económica: el modelo monopolistico y el modelo negocial. J.T. Dunlop, en su ya clásico "Wage Determination Under Trade Unions" considera al sindicato como un monopolio que vende la mercancía (el trabajo) y pretende maximizar sus beneficios entendiendo estos como las rentas salariales de sus afiliados. A.M. Carter, por el contrario, critica el planteamiento de 